\title{
ANÁLISE DA INFLUÊNCIA DA COMPOSIÇÃO DA ÁGUA SOBRE AS MANIFESTAÇÕES PATOLÓGICAS DA ESTRUTURA DE CONCRETO DE UMA BARRAGEM
}

\author{
FONSECA, LUANNA \\ Estudante de Engenharia Civil \\ Faculdade Maria Milza (FAMAM) \\ Bahia; Brasil \\ contato.lfonseca@gmail.com \\ CARVALHO, SÉRGIO \\ Doutor em Geologia Ambiental \\ Faculdade Maria Milza (FAMAM) \\ Bahia; Brasil \\ sergio.carvalho@famam.com.br
}

\author{
MOTA, DANIEL \\ Engenheiro Civil \\ Faculdade Maria Milza (FAMAM) \\ Bahia; Brasil \\ danielandrademota@gmail.com
}

\section{RESUMO}

As barragens são estruturas com finalidade de reter grandes volumes de água, a partir de barramentos transversais ao escoamento de um rio. Geralmente são constituídas em elementos de concreto, armados ou não, e o constante contato com a água pode ser extremamente deletério para o concreto, principalmente se a mesma possuir, na sua composição, elementos que possam acelerar o processo de degradação, seja ele químico ou físico. Sendo assim, este trabalho tem por objetivo identificar as principais manifestações patológicas que acometem as estruturas de concreto de barragens e sua relação com a qualidade da água armazenada, a partir de uma extensa revisão na literatura disponível. Observou-se que fissuras ocasionadas por reação álcali-agregado e corrosão das armaduras, bem como a lixiviação, abrasão e cavitação são as patologias mais recorrentes nas estrutras de barragens de concreto, exercendo a composição da água um papel importante do desenvolvimento destes processos.

Palavras-chave: barragem, concreto, patologia, água.

\section{ABSTRACT}

Dams are structures designed to hold large volumes of water from transverse buses to the river flow. They are usually made of concrete elements, reinforced or not, and constant contact with water can be extremely harmful to concrete, especially if it has in its composition elements that can accelerate the degradation process, whether chemical or physical. Thus, this paper aims to identify the main pathological manifestations that affect the concrete structures of dams and their relationship with the stored water quality, based on an extensive review of the available literature. Cracks caused by alkaline aggregate reaction and reinforcement corrosion, as well as leaching, abrasion and cavitation are the most recurrent pathologies in concrete dam structures, with water quality exercising an important role in this processes development.

Keywords: dam, concrete, pathology, water.

\section{INTRODUÇÃO}

As barragens são elementos estruturais com finalidade de reter volumes, construídas a partir de barramentos transversais ao escoamento de um rio (MARANGON, 2004), com propósito de criação de um reservatório artificial para abastecimento e irrigação, operação de hidroelétricas ou armazenamento de rejeitos oriundos da extração de mineração.

Barragens de abastecimento são necessárias para o fornecimento de água para indústrias e cidades. As grandes cidades brasileiras como exemplos São Paulo, Salvador, Rio de Janeiro etc. dependem dos reservatórios das barragens para que o abastecimento seja garantido a todos ao longo do tempo (MELLO, 2013). 
No entanto, os barramentos muitas vezes por possuírem como material constituinte o concreto, estão expostos a agressividade da água do rio e sucessivamente a manifestações patológicas em sua estrutura. Algumas deteriorações consideradas graves podem vir a gerar acidentes, comprometendo a segurança da barragem. As principais deteriorações em barragens de concreto são fissuras e trincas, expansão, lixiviação, corrosão da armadura, desalinhamentos e deslocamentos diferenciais, infiltração, abrasão e cavitação (CARDIA e KUPERMAN, [200-]).

A composição da água do rio promove processos químicos, físicos, biológicos e processos de sedimentação que podem causar patologias na estrutura de concreto de uma barragem e assim comprometer a segurança da mesma. Nesse contexto, esse artigo visa realizar um breve estudo acerca da influência da composição da água do rio com manifestações patológicas em barragens de concreto.

\section{REVISÃO DE LITERATURA}

\subsection{Poluição ambiental e impactos nos recursos hídricos}

Com o desenvolvimento de uma região, as atividades humanas provocam uma série de danos à natureza, ocasionando desequilíbrios que geram poluição e contaminação do meio ambiente (JUNIOR, 2018).

Segundo a UNEP (2017), os ecossistemas de água doce vêm sofrendo grande poluição, resultado do desenvolvimento socioeconômico que podem ser agravados por impactos nas mudanças climáticas.

Por menores que sejam alguns resíduos produzidos, eles podem ter efeitos significativos em relação a impactos ambientais; essa forma de contaminação pode ser chamada de poluição crônica, onde libera pequenas concentrações constantemente: um exemplo é a disposição de esgoto em rios; porém também existe a poluição aguda que consiste na emissão de uma grande quantidade de poluição de uma só vez, a exemplo de tombamento de carga tóxica; tais efeitos causam alterações físico químicas e biológicas (MACEDO, 2006, BRAGA et. Al, 2007).

Os poluentes hídricos podem ser divididos de acordo com o tipo de resíduo, como orgânicos, minerais, tóxicos, atômicos e mistos (MACEDO, 2006); Heller (2006) acredita que os poluentes podem ser classificados como natureza biológica, química, física e radiológica e Braga et al. (2006) sugerem que ocorre divisão em sólidos em suspensão, calor, radioatividade, orgânicos biodegradáveis, organismos patogênicos, metais, defensivos agrícolas, etc.

Em atividades agropecuárias é comum a contaminação de mananciais, causando um grande impacto degenerador, onde os agroquímicos, nutrientes, sedimentos e dejetos de animais são os resíduos provocadores de poluição resultantes do deflúvio superficial em área agrícola (MERTEN, MINELLA, 2002).

No Brasil, a situação das águas encontra-se em níveis críticos, onde os rios estão contaminados não só por resíduos oriundos de atividades agropecuárias, mas, também, por resíduos industriais, domésticos e mineração (GUIMARÃES, 2001).

\subsection{Parâmetros de qualidade da água}

O Conselho Nacional de Meio Ambiente - CONAMA, através da Resolução CONAMA 357 de 17 de março de 2005, estabeleceu classificação dos corpos de água superficiais e diretrizes ambientais, estabelecendo condições de qualidade dos corpos hídricos, sejam água doce, salgada ou salina. Esses parâmetros de qualidade da água são determinados através de características físicas, químicas e biológicas de amostras em laboratórios (VON SPERLING, 2005) e comparados aos estabelecidos por norma.

Entre os parâmetros físicos, pode-se classificar a turbidez, temperatura, condutividade e transparência. A turbidez ocorre com a modificação da penetração de luz através da difusão e absorção decorrentes de partículas em suspensão, como plâncton, bactérias, argila e silte ou por fontes de poluição (MACEDO, 2006).

A temperatura é dada pela medição da intensidade de calor, que pode ocorrer em situação natural pela radiação solar, ou por poluição de dejetos de industriais. Segundo Junior (2018), processos biológicos, reações químicas e bioquímicas, solubilidade de gases e outros processos ocorridos na água, são influenciados pela temperatura dela.

Com a presença de substâncias dissolvidas em água, onde dissociam em cátions e ânions, denomina-se a condutividade, que é a capacidade de transmitir corrente elétrica (JUNIOR, 2018), cuja variação ocorre entre 50 micromhos/cm até 50.000 micromhos/cm valor, esse atribuído a condutividade da água do mar (MACEDO, 2006).

Quanto à transparência, esta é de extrema importância para penetração de luz no ambiente aquático, uma vez que é de grande relevância para realização de fotossíntese, o que pode vir a afetar todo meio abiótico aquático, já que na penetração da luz, a absorção se transforma em calor (BRAGA, 2007). Para medir a transparência, é utilizado o Disco de Secchi, que consiste em um disco branco com cerca de $20 \mathrm{~cm}$ de diâmetro que vai mergulhando até desaparecer, podendo ir de centímetros em águas turvas até metros como no lago Crater Lake que chega a 40 metros (ODUM, 1971). 
Os parâmetros químicos são definidos como oxigênio dissolvido (OD), demanda química de oxigênio (DQO) e potencial hidrogeniônico $(\mathrm{pH})$. Parâmetros microbiológicos: nutrientes, nitrogênio, fosforo, metais pesados, metais, alumínio, bário, berílio, cadmio, cobalto, cobre, entre outros.

\subsection{Patologias em estruturas de concreto}

Com a evolução da construção civil ao longo do tempo, houve necessidade de estudos em relação ao comportamento das estruturas e materiais utilizados, por conta de deterioração precoce, ou, até mesmo acidentes que ocorreram, sendo importante entender essas situações para de evitar riscos nas edificações (SANTOS, 2014).

No Brasil, a NBR 6118/2007 é a norma regulamentadora acerca das estruturas de concreto armado, onde está previsto a relação de durabilidade de uma edificação, que é a capacidade da estrutura resistir a influências do ambiente em que será instalada, sejam intempéries, ataques químicos ou qualquer processo de degradação.

As manifestações patológicas geralmente ocorrem por falhas durante alguma etapa da edificação, que pode ser no planejamento, projeto, fabricação dos materiais e componentes, execução e uso (TUTIKIAN \& PACHECO, 2013).

Alguns dos principais fatores de deterioração do concreto é a má dosagem, falha no adensamento, falta de homogeneidade na pasta do concreto, espessura do cobrimento de acordo com a classe de agressividade do ambiente, entre outros (VERA, et al. 2008).

Durante a sua preparação, o concreto armado necessita de muitos cuidados, de forma que possa garantir a vida útil e desempenho e, para isso, é de extrema importância a realização de estudos que envolvam traços, dosagem, manuseio, cura e manutenção da estrutura (SANTOS, 2014).

A ausência de planejamento também contribui significativamente para a deterioração das estruturas de concreto armado, pois existem fatores que o projetista acaba por não levar em conta e, ao longo da vida útil, essa estrutura pode vir a ter contato com algum agente não previsto anteriormente, desconsiderando, algumas vezes, pelas condições ambientais futuras (COSTA \& APPLETON, 2002).

Existem diversas classificações de deterioração do concreto, conforme indicado na tabela 1:

Tabela 1: Fatores de deterioração do concreto

\begin{tabular}{|c|c|c|}
\hline & Fatores & Agentes \\
\hline \multirow{7}{*}{1} & \multirow{7}{*}{ Atmosféricos } & Radiação: Solar, nuclear ou térmica \\
\hline & & Temperatura: Elevação, diminuição e ciclos \\
\hline & & Água: sólida, líquida ou vapor \\
\hline & & Constituintes normais do ar: oxigênio, ozônio e CO2 \\
\hline & & Poluentes do ar: Gases, neblina e partículas de impurezas \\
\hline & & Ciclos de gelo e degelo \\
\hline & & Ventos \\
\hline \multirow{2}{*}{2} & \multirow{2}{*}{ Biológicos } & Vegetais: Algas, fungos, cogumelos, plantas e árvores \\
\hline & & Animais: Insetos, pássaros, moluscos e roedores \\
\hline \multirow{3}{*}{3} & \multirow{3}{*}{ Esforços } & Permanentes: Decorrentes de ação da gravidade \\
\hline & & Variáveis: Ação física de água, vento, frenagem, etc. \\
\hline & & Raros: Explosões. Incêndios, choques, etc \\
\hline \multirow{2}{*}{4} & \multirow{2}{*}{ Incompatibilidade } & Químicos \\
\hline & & Físicos \\
\hline \multirow{2}{*}{5} & \multirow{2}{*}{ Uso } & Desgaste por uso normal e abuso do uso \\
\hline & & Procedimentos de instalação e manutenção \\
\hline
\end{tabular}

Fonte: Fortes (1994)

A deterioração do concreto por alterações químicas; geram efeitos físicos na estrutura como, por exemplo, o aumento de volume de uma barra de aço quando oxidada, o que gera o desplacamamento da massa de concreto (PEREIRA, 2014). Em casos de processo físicos de deterioração, pode-se citar ações de cargas excessivas, vibrações e erosões.

As principais causas de fenômenos químicos que comprometem as estruturas de concreto armado são a corrosão da armadura devido à carbonatação e a reação álcali-agregado. Outras reações químicas que também são responsáveis pela degradação do concreto são, o ataque de água mole no hidróxido de cálcio e C-S-H presente nos 
cimentos Portland hidratados, cloreto de cálcio, sulfato de cálcio, bicarbonato de cálcio, oxalato de cálcio, ataque por sulfato formando etringita e gesso, etc. (MEHTA \& MONTEIRO (2008).

Na tabela 2 abaixo, são demonstrados a velocidade de ataque de alguns produtos químicos no concreto:

Tabela 2: Efeitos de alguns produtos químicos no concreto

\begin{tabular}{|c|c|c|c|c|c|}
\hline $\begin{array}{l}\text { Velocidade de } \\
\text { ataque a } \\
\text { temperatura } \\
\text { ambiente }\end{array}$ & $\begin{array}{c}\text { Ácidos } \\
\text { inorgânicos }\end{array}$ & $\begin{array}{c}\text { Ácidos } \\
\text { orgânicos }\end{array}$ & Soluções alcalinas & Soluções de sais & Diversos \\
\hline Rápida & $\begin{array}{c}\text { Clorídrico } \\
\text { Fluorídrico } \\
\text { Nítrico } \\
\text { Sulfúrico }\end{array}$ & $\begin{array}{l}\text { Acético } \\
\text { Fórmico } \\
\text { Láctico }\end{array}$ & - & Cloreto de alumínio & - \\
\hline Moderada & Fosfórico & Tânico & $\begin{array}{l}\mathrm{Na}(\mathrm{OH}) \\
>20 \%\end{array}$ & $\begin{array}{l}\text { Nitrato de amônio } \\
\text { Sulfato de amônio } \\
\text { Sulfato de sódio } \\
\text { Sulfato de magnésio } \\
\text { Sulfato de Cálcio }\end{array}$ & $\begin{array}{l}\text { Bromo (gás) } \\
\text { Concentrado de } \\
\text { sulfito }\end{array}$ \\
\hline Lenta & Carbônico & - & $\mathrm{Na}(\mathrm{OH}) 10$ a $20 \%$ & $\begin{array}{l}\text { Cloreto de amônio } \\
\text { Cloreto de } \\
\text { magnésio } \\
\text { Cianeto de sódio }\end{array}$ & $\begin{array}{l}\text { Cloro (gás) } \\
\text { Água do mar } \\
\text { Água pura }\end{array}$ \\
\hline Desprezível & - & $\begin{array}{l}\text { Oxálico } \\
\text { Tartárico }\end{array}$ & $\begin{array}{c}\mathrm{Na}(\mathrm{OH}) \\
<10 \% \\
\text { Hipoclorito de sódio } \\
\mathrm{NH}_{4} \mathrm{OH} \\
\end{array}$ & $\begin{array}{c}\text { Cloreto de cálcio } \\
\text { Cloreto de sódio } \\
\text { Nitrato de zinco } \\
\text { Cromato de sódio }\end{array}$ & Amônia (líquida) \\
\hline
\end{tabular}

Fonte: NEVILLE (1992)

Os fenômenos biológicos também podem ser responsáveis na degradação de uma estrutura de concreto armado, geralmente ocorrem naquelas que estão em contato, por exemplo, com esgotos sanitários, devido a ação de bactérias sulfo-oxidantes, Thiobacillus spp, (PEREIRA, 2014).

Segundo Silva \& Pinheiro (2006), o concreto é biorreceptivo, ou seja, o material fornece condições de ser colonizado por um ou mais grupos de organismos vivos, então ele se torna susceptível a ataques microbiológicos devido às suas condições de rugosidade, porosidade e umidade que, a depender das condições ambientais de onde se encontra e com a presença de água, temperatura e luminosidade, podem facilmente promover a deterioração desse concreto.

As principais manifestações patológicas das estruturas de concreto são a fissuração, corrosão de armaduras, corrosão devido ao ataque por cloretos, corrosão por carbonatação, manchas e eflorescências.

Segundo a NBR 6118:2007 os mecanismos preponderantes de deterioração do concreto são a lixiviação (águas puras e ácidas), expansão (sulfatos e magnésio); a deterioração da armadura corresponde a processos corrosivos devido à carbonatação e a corrosão pelo alto teor de íon cloro (cloreto).

As estruturas de concreto armado inevitavelmente sofrem com a fissuração, devido a grande variabilidade e a baixa resistência que o material apresenta quando está submetido aos esforços de tração (PEREIRA, 2014). A NBR 6118/2007 estabelece parâmetros de limites de abertura dessas fissuras, afim de obter bom desempenho em relação a proteção quanto a corrosão, uma vez que essas fissuras são portas de entrada para ataque da armadura do concreto.

A corrosão das armaduras é um dos principais problemas patológicos responsáveis pela rapidez de degradação das estruturas. A corrosão é a transformação de um metal em íon metálico, através da interação química ou eletroquímica no ambiente em que está situado (CASCUDO, 2005). Normalmente a corrosão se inicia com ataques de agentes agressivos, como íons cloretos em áreas litorâneas ou dióxido de carbono presente na poluição urbana (ABOSRRA, ASHOUR e YOUSEFFI, 2011).

A corrosão por ataque de cloretos ocorre com a exposição do concreto em ambientes prejudiciais, como determinados tipos de água subterrâneas, efluentes industriais e domésticos, onde nesses ambientes, encontram-se os íons cloretos e sulfatos que danificam as estruturas de concreto (HUANG, BAO e YAO, 2004). Nesse processo de corrosão, ocorre com a penetração de íons cloreto na massa de concreto, geralmente por contaminação de materiais (água ou agregados), névoa salina, água do mar e processos industriais (PEREIRA, 2014). 
O processo de corrosão por carbonatação é dado por um processo físico-químico, onde os compostos de cimento, hidratados ou não, são substituídos por carbonatos, através de reações com dióxido de carbono (CO2), dióxido de enxofre $\left(\mathrm{H}_{2} \mathrm{~S}\right)$, etc. (PAULETTI, 2004). Essa reação resulta em redução do pH do concreto com valores abaixo de 9,0. Abaixo dessa faixa, os compostos hidratados do cimento com predisposição a carbonatação são o hidróxido de cálcio $\left(\mathrm{Ca}(\mathrm{OH})_{2}\right)$, o hidróxido de sódio $(\mathrm{NaOH})$ e o hidróxido de potássio $(\mathrm{KOH})$, assim como nos silicatos alcalinos (FIGUEREDO, 2005).

Outro tipo de patologia muito comum em estruturas em contato com água, intempéries e poluição são as manchas e eflorescências. As manchas ocorrem no processo de retenção da umidade na estrutura, apresentando coloração escura devido a presença de fungos e mofos no concreto e coloração marrom avermelhada ou esverdeada nas armaduras (FONSECA, 2007). A eflorescência é o depósito de sais nas superfícies do concreto, oriundo do carregamento dos sais originários da hidratação do cimento e geralmente ocorrem nos locais onde há facilidade de percolação da água, seja em juntas ou em fissuras (SUPRENANT, 1992).

De acordo com Andrade (2011), ácidos orgânicos e minerais, óleos, substâncias fermentadas, esgoto industrial podem atacar diretamente o concreto, ou seja, a agressividade do ambiente está completamente relacionada a degradação da estrutura de concreto armado, como pode ser observado na tabela 3.

Tabela 3 - Principais mecanismos de deterioração das estruturas de concreto armado

\begin{tabular}{|c|c|c|c|}
\hline \multicolumn{2}{|c|}{ Agressividade do ambiente } & \multicolumn{2}{|c|}{ Consequências sobre a estrutura } \\
\hline Natureza do processo & Condições particulares & $\begin{array}{l}\text { Alterações iniciais } \\
\text { na superfície do } \\
\text { concreto }\end{array}$ & Efeitos a longo prazo \\
\hline Carbonatação & UR $60 \%$ a $85 \%$ & Imperceptível & $\begin{array}{l}\text { Redução do pH, corrosão de } \\
\text { armaduras e fissuração superficial }\end{array}$ \\
\hline Lixiviação & Atmosfera ácida, águas pura & $\begin{array}{l}\text { Eflorescências, } \\
\text { manchas brancas }\end{array}$ & $\begin{array}{c}\text { Redução do pH, corrosão de } \\
\text { armaduras e desagregação } \\
\text { superficial }\end{array}$ \\
\hline Retração & $\begin{array}{l}\text { Umedecimento e secagem, } \\
\text { ausência de cura } \\
\text { UR baixa }(<50 \%)\end{array}$ & Fissuras & $\begin{array}{l}\text { Fissuração e corrosão de } \\
\text { armaduras }\end{array}$ \\
\hline Fuligem & $\begin{array}{l}\text { Particulas em suspensão na } \\
\text { atmosfera urbana e industrial }\end{array}$ & Manchas escuras & $\begin{array}{l}\text { Redução do pH e corrosão de } \\
\text { armaduras }\end{array}$ \\
\hline Fungos e mofo & $\begin{array}{c}\text { Temperaturas altas }\left(>20^{\circ} \mathrm{C} \text { e }\right. \\
\left.<50^{\circ} \mathrm{C}\right) \text { com UR }>75 \%\end{array}$ & $\begin{array}{l}\text { Manchas escuras e } \\
\text { esverdeadas }\end{array}$ & $\begin{array}{l}\text { Redução do pH, corrosão de } \\
\text { armaduras e desagregação } \\
\text { superficial }\end{array}$ \\
\hline Concentração salina & Atmosfera marinha e industrial & Imperceptível & $\begin{array}{c}\text { Despassivação e corrosão de } \\
\text { armaduras }\end{array}$ \\
\hline Sulfatos & Esgoto e águas servidas & Fissuras & $\begin{array}{c}\text { Expansão, fissuras, desagregação } \\
\text { do concreto e corrosão de } \\
\text { armaduras }\end{array}$ \\
\hline Álcali-agregado & $\begin{array}{l}\text { Composição do concreto } \\
\text { umidade, UR > 95\% }\end{array}$ & $\begin{array}{c}\text { Fissuras } \\
\text { gel ao redor do } \\
\text { agregado graúdo }\end{array}$ & $\begin{array}{c}\text { Expansão, fissuras, desagregação } \\
\text { do concreto e corrosão de } \\
\text { armaduras }\end{array}$ \\
\hline
\end{tabular}

Fonte: (Durabilidade e Vida Útil das Estruturas de Concreto, 2011)

De acordo com a agressividade do ambiente, a estrutura pode sofrer tanto com alterações iniciais na superfície do concreto, quanto a longo prazo. O contato do concreto armado com água contaminada pode gerar processos químicos e físicos, podendo vir a acelerar a degradação do concreto e diminuir a sua vida útil. 


\subsection{Relação da qualidade deaágua do rio com a estrutura de concreto}

\subsubsection{Mecanismos de transportes de fluidos}

O concreto armado possui uma grande facilidade de permeabilidade de fluidos na estrutura, sendo necessário no momento de projeto, avaliar todas condições de agressividade ao qual estará exposto, para que seu comportamento seja desejável no período de vida útil.

Segundo Neville (1997), a degradação mecânica e contato com fluidos, estão ligados a todos processos de deterioração de estruturas, onde a porosidade não é o único fator determinante, mas também a forma, distribuição, dimensão, tortuosidade e continuidade de poros.

Para Crauss (2010), os fluidos que podem vir a penetrar no concreto são o oxigênio, dióxido de carbono, água pura ou contaminada, sendo que todos são responsáveis por processos de corrosão em armaduras, onde através da permeabilidade, pode ocorrer o transporte de água contaminada por exemplo para o interior do concreto, podendo comprometer a estrutura. Os cloretos podem penetrar no concreto através de absorção capilar de fluidos, difusão ou migração

A absorção capilar é uma entrada para agentes agressivos, ocorre através do transporte de líquidos pelos poros capilares através da tensão superficial do líquido, onde a absorção dar-se-á em poros parcialmente ou totalmente secos (HELENE, 1993). A entrada de íons cloreto por capilaridade, por exemplo, ocorre quando estão dissolvidos em água, onde é bastante comum ocorrer em concretos expostos a ciclos de molhagem e secagem (SANTOS, 2000).

Na difusão, a penetração de cloretos ocorre com o preenchimento dos poros com água, não sendo necessário a movimentação de água nesse processo, e sim um gradiente de concentração de íons entre o interior do concreto com a sua superfície (CRAUSS, 2010).

A migração acontece a movimentação de substâncias que possuem carga elétrica, gerada pela aplicação de uma diferença de potencial elétrico e esse mecanismo utilizado em técnicas de dessalinização e re-alcalinização, passaram a ser aplicados também em estruturas danificadas, afim de permitir exposição do concreto a um campo elétrico (HISADA et. al 1999).

\subsubsection{Processos químicos de deterioração do concreto}

No meio ambiente existem substâncias que podem vir a penetrar na massa de concreto endurecido, através da relação entre umidade e temperatura, que podem causar reações químicas de efeitos nocivos, sendo os mecanismos mais comuns de deterioração química o ataque por sulfatos, água do mar, ácidos, água pura e gás carbônico.

Os sulfatos são elementos bastante agressivos, sendo que em sua forma sólida não possuem poder de atacar o concreto; porém quando em solução, os sulfatos de magnésio, potássio, sódio, cálcio e amônio podem causar sérios danos ao concreto. Os sulfatos podem ser localizados em solos argilosos, diluídos em água de lençol freático ou em aterros. A velocidade do ataque depende de fatores como concentração, permeabilidade do concreto e quantidade de água no processo para reação (BRANDÃO,1998).

$\mathrm{O}$ ataque por ácido ocorre no contato do concreto com soluções onde o pH é inferior a 6,5. Pode-se citar como ácidos que atacam o concreto o sulfúrico, fosfórico, clorídrico, nítrico, lático, acético, tartárico fluorídrico, oxálico. A deterioração, sejam por ácidos orgânicos ou inorgânicos, resultam de reações entre compostos de cálcio do cimento endurecido, silicato, aluminato e hidróxido de cálcio, convertidos em sais de cálcio (BRANDÃO, 1998). Águas provenientes de minas, de indústrias, presença de dejetos de esgotos ou a oxidação de sulfeto de ferro de solos argilosos, são exemplos de componentes que possuem elementos ácidos capazes de causar deterioração do concreto.

A presença de oxigênio dissolvido é essencial para corrosão de aço nas armaduras do concreto armado. De acordo com Bauer et al. (1990), existem duas formas do oxigênio atingir a armadura, sendo pelo ar ou pela decomposição da água do concreto, em razão de uma diferença potencial.

$\mathrm{O}$ ataque por dióxido de carbono $\left(\mathrm{CO}_{2}\right)$ é muito recorrente em estruturas de concreto armado, onde com a exposição da estrutura a esse elemento, ocorre a redução da alcalinidade, ou seja, diminui o pH do concreto que é responsável pela proteção das armaduras contra a corrosão (BRANDÃO, 1998). $\mathrm{O} \mathrm{CO}_{2}$ pode ser encontrado na atmosfera com maior intensidade em áreas urbanas e industriais, porém também pode ser encontrado dissolvido em água, por exemplo em chuvas ácidas.

A corrosão ocasionada por íons cloreto é considerada como uma das principais causas de deterioração de estruturas (WEE et al., 2000). Divergindo do ataque por $\mathrm{CO}_{2}$ ou soluções ácidas, os cloretos podem vir a prejudicar as armaduras mesmo nas condições de alta alcalinidade da solução de poros, já que os íons não consumidos no processo de corrosão, mantem-se disponíveis para novas reações (CRAUSS, 2010). 


\subsubsection{Processos físicos de deterioração do concreto}

Em processos físicos de deterioração de concreto, pode-se levar em conta o congelamento de água contido nos poros e cristalização de sais. No Brasil, o processo de congelamento não é muito típico, por se tratar de um país com clima tropical (BRANDÃO, 1998).

No entanto, a cristalização de sais é bastante recorrente, por exemplo, em estruturas expostas a água do mar, onde primeiramente ocorre a penetração da água que percola pelos poros, em seguida a evaporação dessa água, deixando os sais entranhados no concreto, causando diversas patologias a exemplo das eflorescências.

Os principais agentes físicos de deterioração do concreto, estão relacionados aos carregamentos em que a estrutura está submetida, mudanças e volume e exposição a mudanças extremas de temperatura, que podem causar desgaste da superfície por abrasão, erosão, cavitação ou fissuração (SANTOS, 2014).

A perda por abrasão é uma perda gradual e contínua da argamassa superficial e de agregados, dada pelo efeito de atrito, geralmente por tráfego de pessoas, veículos ou ação do vento. A erosão é provocada por ação da água em movimento, arrastando partículas sólidas que quando se choca com o concreto, ocorre o desgaste, o que é muito comum em barragens, calhas de vertedouros, pilares de ponte etc. A cavitação é a perda de massa causada pela formação de vapor, geralmente ocorre por mudanças repentinas de direção de fluxo de água; esse tipo de desgaste geralmente se encontra em vertedouro de barragem ou condutos forçados (SANTOS,2014).

\subsubsection{Processos biológicos de deterioração do concreto}

Os processos de degradação biológica ocorrem através de proliferação de parasitas, sejam de origem animal ou vegetal ou por organismos microscópicos. Em regiões próximas a saída de esgoto, é muito comum a ocorrência desse tipo de processo, já que possui grande quantidade de nutrientes essenciais para sobrevivência desses organismos. O resultado dessa proliferação é o aumento do grau de saturação por retenção de uma maior quantidade de água e com a penetração desses seres no concreto, ocorrem as fissurações (BRANDÃO, 1998).

Os processos biológicos de deterioração, podem gerar deterioração mecânica como fissurações e ataques químicos, através de processos de decomposição causados por esses organismos. As raízes de plantas por exemplo, podem vir a causar processos mecânicos de fissurações e nesses pontos de fragilidade, onde há um aumento da umidade do concreto, ocorre a instalação de organismos, que no processo de decomposição, geram ataques químicos por ação de ácidos orgânicos e sulfatos, que podem comprometer a estrutura (BRANDÃO, 1998).

\subsection{Barragens de concreto}

As barragens são estruturas construídas de forma transversal a um curso d'água, que tem como finalidade a elevação do nível d'água para criação de reservatórios artificias, a exemplo uma barragem de abastecimento ou retenção de volumes como em barragens de rejeitos (ORO, 2016).

Existem diversos tipos de barragens (Figura 1), que são classificadas de acordo com a forma física, tipos de material constituintes, a sua empregabilidade para cada função etc.

\section{Figura 1 - Fluxograma dos tipos de barragens}

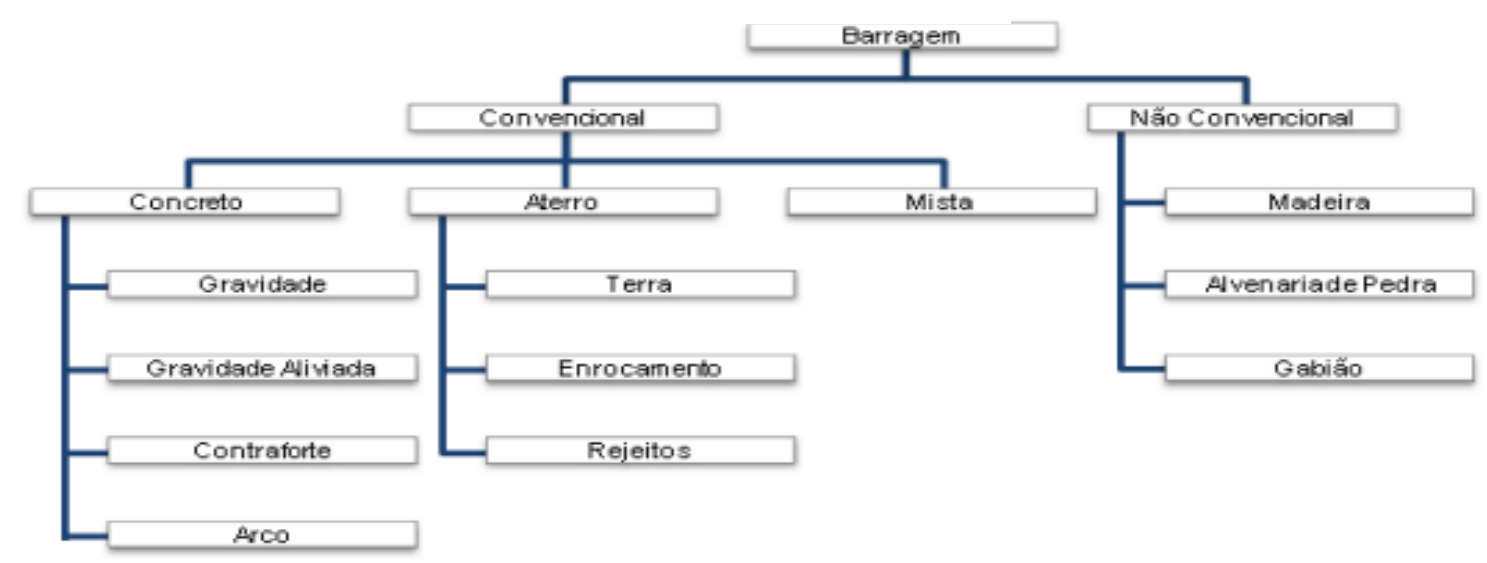

Fonte: Índice de monitoramento do comportamento estrutural dos blocos de concreto de barragens - uma abordagem multivariada (oro, 2016) 
As barragens de aterro são construídas a partir da disponibilidade de solo (argila, silte ou areia) ou rejeitos. As principais vantagens dessas construções estão ligadas a fácil obtenção de material, uso de equipamentos mais simples e menor custo (FRANCO, 2008). São muito utilizadas para irrigação e retenção de rejeito oriundos de mineração, porém, possui como desvantagem, a ação erosiva causadas por ondas de cheia, que podem danificar a estrutura (CIRILO, 2003).

As barragens de terra-enrocamento, são combinações entre aterros com rocha sã, geralmente são recomendadas em locais onde a fundação possui baixa resistência (FRANCO, 2008). Porém, por se tratar de uma barragem de terra, estão sujeitas a destruição em superenchentes, caso não possua capacidade de escoamento adequada (BUREAU OF RECLAMATION, 1987).

As barragens de concreto são estruturas rígidas, classificadas como contrafortes, arco, gravidade e gravidade aliviada. Barragens de gravidade são constituídas de pedra ou alvenaria e concreto, onde o peso próprio tem função de resistir ao peso da água, barragens de arco são construídas com concreto e rocha sã, geralmente utilizadas em vales estreitos, onde a força da água que atua no arco é transmitida para as paredes do vale e barragens de contraforte, também conhecida como gravidade aliviada, tem como característica, suportar o peso da água pelos contrafortes ou suportes verticais e assim transmitir essa carga para as fundações (POSSAN, [200-]). As técnicas mais utilizadas para essas construções são de CCV - Concreto Convencional Vibrado, CCR - Concreto Compactado com Rolo (CIRILO, 2003).

Em uma barragem de gravidade, os principais componentes para seu funcionamento são a bacia de dissipação, paramento de jusante, ombreiras, crista e vertedouro, conforme indicado abaixo:

Figura 2 - Componentes de uma barragem de gravidade
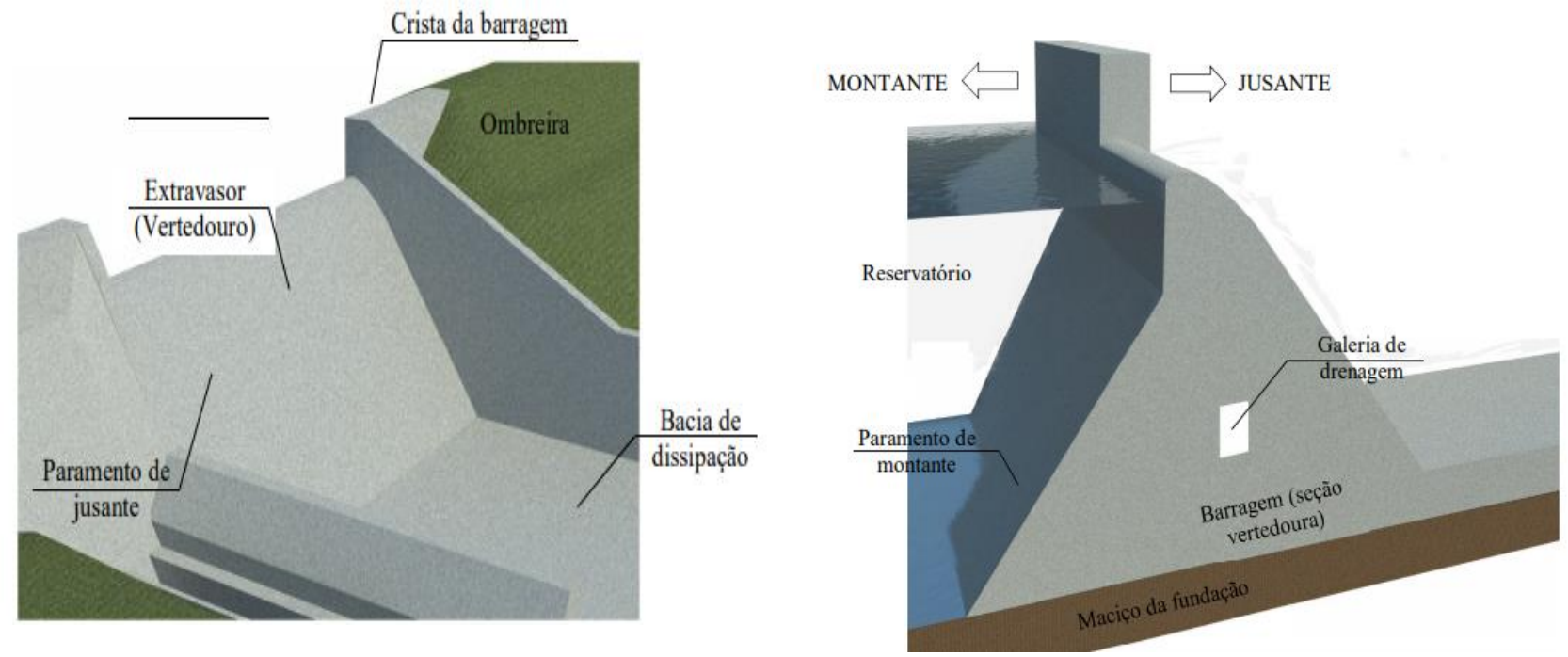

Fonte: (Moura, 2016)

\section{METODOLOGIA}

Este estudo constitui uma revisão de literatura de caráter análitico acerca da relação de manifestações patológicas em barragens de concreto com a composição da água do rio na qual está em contato. A coleta de dados ocorreu no período de outubro a dezembro de 2019 através das bases de dados SciELO, Periódicos Capes e Google Acadêmico. Foram analisados quinze artigos, oito dissertações, quatro teses e diversos livros, disponibilizados nas plataformas citadas anteriormente. Para encontrar os materiais adequados para realização dessa pesquisa, foram utilizados como filltro nos bancos de dados, palavras como Barragens, Concreto, Patologias, Deterioração do Concreto, Reação álcali-agregado, entre outros. Após a seleção do material, foi realizada a leitura exploratória, leitura seletiva para escolha do material que melhor se adequa aos objetivos dessa pesquisa, análise dos materiais e por fim o desenvolvimento deste artigo. 


\section{RESULTADOS E DISCUSSÃO}

Após a análise dos materiais selecionados, pode-se perceber que a composição da água tem extrema relação com as manifestações patológicas em uma barragem de concreto. Como o concreto possui uma facilidade de permeabilidade de fluídos, vem a ocorrer a degradação mecânica decorrente da penetração de oxigênio, dióxido de carbono, água pura ou contaminada e penetração de cloretos através de absorção capilar de fluídos (CRAUSS, 2010).

O ambiente no qual a estrutura de uma barragem está instalada, já possui substâncias que muito provavelmente irá vir a penetrar na massa do concreto endurecido e através da combinação entre umidade e temperatura ocorrem as reações químicas mais comuns como ataques por sulfatos, salinidade da água, ácidos, água pura e gás carbônico (NEVILLE, 1992). Em ambientes expostos a poluição, é muito provável que a intensidade dessa agressão seja muito maior, pois pode ocorrer aumento da temperatura da água, contaminação por dióxido de carbono proveniente da poluição urbana, potencialização das reações químicas como ataque por sulfatos no concreto, surgimento de manchas e eflorescências, entre outros (MACEDO, 2006, BRAGA et. Al, 2007).

O sulfato é encontrado em solos argilosos e diluídos em água, ou seja, em ambiente que facilmente se encontra as instalações de uma barragem. A acidez da água também é um fator muito relevante para deterioração do concreto, pois com o pH abaixo de 6,5 já ocorrem as reações, podendo ser ácidos orgânicos ou inorgânicos e quando há presença de poluição como despejo de esgotos podem potencializar a deterioração do concreto (BRANDÃO, 1998).

Com a ocorrência de processos químicos de degradação, consecutivamente ocorrem os processos físicos que podem ser constatados como mudança de volume que podem causar desgaste da superfície por abrasão, erosão, cavitação e fissuração, processos mais ocorrentes no concreto. A erosão e cavitação são os processos que ocorrem com maior intensidade, visto que a erosão ocorre com a ação da água em movimento ao chocar-se com o concreto e a cavitação ocorre com mudanças de direção de fluxo de água (SANTOS, 2014).

Além dos dois processos citados anteriormente, os processos de degradação biológica também ocorrem no concreto através da proliferação de parasitas e organismos microscópicos. Em locais poluídos e principalmente em contato com esgoto é muito comum que ocorra esse processo, porém não descartando a ocorrência em ambiente natural, pois as raízes de plantas por exemplo promovem processos de decomposição que podem vir a causar ataques químicos em função dos processos biológicos (BRANDÃO, 1998).

\section{CONSIDERAÇÕES FINAIS}

Ao fim dessa pesquisa foi possível identificar que de fato as manifestações patológicas que ocorrem no concreto têm relação com a composição da água, pois através do contato com a água poluída ou até mesmo nos processos de sedimentações que ocorrem no rio, causam efeitos degenerativos na estrutura. Desse modo, é importante conhecer e mapear esses processos, visto que diante dos recentes acontecimentos que envolve rompimentos de barragens, veio a surgir uma preocupação em relação a segurança das mesmas.

A identificação dos processos que podem ocorrer na estrutura é de extrema importância para evitar que tais patologias possam vir a causar danos de proporção maior como falhas e rompimentos da estrutura de uma barragem que poderiam causar impactos ao meio ambiente, população e economia da região, pois uma vez identificadas, pode-se realizar os procedimentos necessários de recuperação dos desgastes e deteriorações ocorrentes.

\section{REFERÊNCIAS}

ABNT NBR 6118. (31 de março de 2007). Projeto de Estruturas de Concreto - Procedimento.

ABOSRRA, L., ASHOUR, A., YOUSEFFI, M. (23 de may de 2011). Corrosion of steel reinforcement in concrete of diferente compressive strenghs. Construction and Building Materials, pp. 3915-3925.

AGÊNCIA NACIONAL DE ÁGUAS - ANA. Sistema de Informações Hidrológicas. Brasília: 2013. Disponível em: 〈https://www.snirh.gov.br/hidroweb/publico/apresentacao.jsf〉. Acesso em 01 nov. 2019.

ANDRADE, C.; CASTELLOTE, M.; D'ANDREA, R. Measurements of Ageing Effect on Chloride Diffusion Coefficients in Cementitious Matrices. Journal of Nuclear Materials, v. 412, n. 1, p. 209-216, 2011.

BAUER, E.; ARAÚJO, A. M; CAVALCANTI, E. F. Algumas considerações sobre técnicas eletroquímicas de monitoramento da corrosão em estruturas de concreto armado. In: SEMINÁRIO NACIONAL DE CORROSÃO NA CONSTRUÇÃO CIVIL, 4., 1990, Rio de Janeiro. Anais... Rio de Janeiro, ABRACO, 1990. 
BRAGA, B.; HESPANHOL, I.; CONEJO, J.G.L.; MIERZWA, J.C.; BARROS, M..T.L.; BRANDÃO, A. M. da S.. Qualidade e durabilidade das estruturas de concreto armado - Aspectos relativos ao projeto. Dissertação de mestrado em Engenharia de Estruturas. Universidade de São Paulo. São Paulo, 1998.

BUREAU OF RECLAMATION - US. Department of the Interior. Design of small dams. Denver, Colorado, Estados Unidos, 1987.

CARDIA, R. J.; KUPERMANN, S. Curso de segurança de barragens: Módulo II Inspeção e auscultação de barragens. ICBA, [200-].

CASCUDO, O. (2005). Inspeção e Diagnóstico de Estruturas de Concreto com Problemas de Corrosão da Armadura. In: O. CASCUDO, \& G. C. ISAIA (Ed). Concreto: Ensino, Pesquisa e Realizações (Vol. 2, p. 1579). São Paulo: IBRACON.

CIRILO, J.; ABREU, G. F. H.; COSTA, M. R. Soluções para o suprimento de água de comunidades rurais difusas no semiárido brasileiro: avaliação de barragens subterrâneas. Revista Brasileira de Recursos Hídricos. Volume 8 n.4. 2003. p. 5-24.

COSTA, A., \& APPLETON, J. (2002). Case studies of concrete deterioration in a marine enviroment in Portual. Cemente \& Concrete Composites, pp. 169-179.

CRAUSS, Camila. Penetração de cloretos em concretos com diferentes tipos de cimento submetidos a tratamento superficial. Dissertação de mestrado. Santa Maria, RS, Brasil, 2010. Disponível em:

<https://repositorio.ufsm.br/bitstream/handle/1/7754/CRAUSS,\%20CAMILA.pdf〉. Acesso em: 10 de outubro de 2019.

FIGUEIREDO, E. P. (2005). Efeitos da Carbonatação e de Cloretos no Concreto.

FONSECA, R.P. (Junho de 2007). A estrutura do Instituto Central de Ciências: aspectos históricos, científicos e tecnológicos de projeto, execução, intervenções e proposta de manutenção. A Estrutura do Instituto Central de Ciências: aspectos históricos, científicos e tecnológicos de projeto, execução, intervenções e proposta de manutenção. Brasília, DF, Brasil.

FORTES F., Jorge. Patologia e terapêutica das construções: um panorama.

FRANCO, Carlos Sérgio Souza Pinto de Almeida. Segurança de barragens: aspectos regulatórios. 2008. 136 f. Dissertação (Mestrado em Ciências Agrárias) - Universidade Federal de Goiás, Goiás, 2008.

GUIMARÃES, S. L. Jornal da UNESP, Ano XVI, N. 158, Julho/Agosto, 2001.

HELENE, P. R. L. Contribuição ao estudo da corrosão em armaduras de concreto armado. 1993. 271f. Tese (Livre Docência em Engenharia) - Escola Politécnica da Universidade de São Paulo - EPUSP, São Paulo, 1993.

HELLER, L.; PÁDUA, V.L. (Ed.). Abastecimento de água para consumo humano. Belo Horizonte: UFMG, 2006. P. 153-215.

HISADA, H.; NAGATAKI, S.; OTSUKI, N. Evaluation os mineral admixture on the viewpoint of chloride ín migration through mortar. Cement \& Concrete Composites, Great Britain: Elsevier Science, v.21, p.443-448, 1999.

HUANG, P., BAO, Y., \& YAO, Y. (11 de June de 2004). Influence of HCL corrosion on the mechanical properties of concrete. Cement and Concrete Research, pp. 584589.

In: G. C. ISAIA, \& G.C. ISAIA (Ed.), Concreto: Ensino, Pesquisa e Realizações (Vol. Volume 2, pp. 828-855) São Paulo, SP, Brasil: IBRACON.

INSTITUTO DO MEIO AMBIENTE E RECURSOS HÍDRICOS (BR). Portaria INEMA no 16.481, de 11 de julho de 2018 . 
JUNIOR, P. A. do V.. Análise da qualidade da água dos principais afluentes para gestão da futura barragem de Miringuava de abastecimento público.

MACEDO, J.A.B. Introdução à química ambiental. Juiz de Fora: CRQ-MG, 2006.

MARANGON, M.. Barragens de Terra e Enrocamento. Disponível em: http://www.ufjf.br/nugeo/files/2009/11/togot_unid05.pdf>. Acesso em: 15 set. 2019.

MEDEIROS, M. H. F. de; ANDRADE, J. de O; HELENE, P. Durabilidade e vida útil das estruturas de concreto. Concreto: Ciência e Tecnologia. Capítulo 22. IBRACON, 2011.

MEHTA, P. K., \& MONTEIRO, P. M. (2008). Concreto: Microestrutura, Propriedades e Materiais. São Paulo, Brasil: IBRACON.

MELLO, F. M. de. A importância dos reservatórios formados por barragens. Revista Newsletter CBCB, 2013.

MERTEN, G.H.; MINELLA, J.P. Qualidade da água em bacias hidrográficas rurais: um desafio atual para a sobrevivência futura. Revista Agroecologia e Desenvolvimento Rural Sustentável, Porto Alegre, v.3, n.4, 2002.

MOURA, Flávia M. P. Estudo comparativo da verificação da estabilidade de barragens de gravidade de concreto compactado a rolo a partir de modelagem em elementos finitos e de métodos analíticos. Salvador/BA, 2016.

NEVILLE, A. M. Propriedades do concreto. 2. Ed. São Paulo: Pini, 1997. 828p.

ORO, S. R. Índice De Monitoramento Do Comportamento Estrutural Dos Blocos De Concreto De Barragens - Uma Abordagem Multivariada. Tese do programa de pós-graduação em Métodos Estatísticos Aplicados a Engenharia. Universidade Federal do Paraná. Curitiba/PR, 2016.

PÁDUA, V.L.; FERREIRA, A.C.S. Qualidade da água para consumo humano. In: PAULETTI, C. (2004). Análise comparativa de procedimentos para ensaios acelerados de carbonatação. Porto Alegre, Rio Grande do Sul, Brasil: UFRGS.

PEREIRA, H. W.B. Identificação das condições gerais de conservação nos reservatórios integrantes do sistema de abastecimento de água de Natal. Disponível em:

<http://repositorio.ufrn.br:8080/jspui/bitstream/123456789/14857/1/HazenWBP_DISSE RT.pdf〉. Acesso em: 30 de set de 2019.

POSSAN, E.. Curso de segurança de barragens: Módulo I -Barragens: Aspectos Legais, Técnicos e Sócioambientais. ICBA, [200-].

PRODANOV, C.C.; DE FREITAS, E. C. Metodologia do trabalho científico: Métodos e Técnicas da Pesquisa e do Trabalho Acadêmico. $2^{\mathrm{a}}$ edição. Editora Universidade Feevale. Rio Grande do Sul, 2013.

PRODANOV, C.C.; DE FREITAS, E. C. Metodologia do trabalho científico: Métodos e Técnicas da Pesquisa e do Trabalho Acadêmico. $2^{a}$ edição. Editora Universidade Feevale. Rio Grande do Sul, 2013 Revista da "Jornada Professor Hernani Sobral”, Salvador, v. único, p. 53-60, 1994.

SANTOS, C. F dos. Patologia de estruturas de concreto armado. Universidade Federal de Santa Maria, 2014. Santa Maria/RS.

SANTOS, C.S.V. Formação de camadas superficiais adensadas em solo argiloso em resposta a flutuações de umidade. Viçosa, Universidade Federal de Viçosa, 2000. 70p. (Tese de Doutorado). 
SILVA, M. R., \& PINHEIRO, S. d. (2006) Biodeterioração do Concreto. In: M.R. SILVA, S.M. PINHEIRO, \& G. ISAIA (Ed.), Concreto: Ensino, Pesquisa e Realizações (p.1579). São Paulo: IBRACON.

SPENCER, M.; PORTO, M.; NUCCI, N.; JULIANO, N.; EIGER, S. Introdução à Engenharia Ambiental. 2ª ed., Ed. Prentice Hall: São Paulo, 2005.

SUPRENANT, B. A. (1992) Efflorescence - Minimizing unsightly staining.

TUTIKIAN, B., \& PACHECO, M. (março de 2013). Inspeção, Diagnóstico e Prognóstico na Construção Civil. Inspección, Iagnóstico y Prognóstico em la Construcción Civil. Mérida, México: ALCONPAT.

UNEP (United Nations Environment Programme). Stockholm Convention. 2009. Protection human health and the environment from persistent organic pollutants. Disponível em:<http://chm.pops.int/TheConvention/ThePOPs/ListingofPOPs.> Acesso em: 13 de out. 2019.

VERA, R., VILlARroel, M., CARVAJAL, A. M., VERA, E., ORTIZ, C. (2008). Corrosion Products of Reinforcement in Concrete in Marine and Industrial Enviroments. Materials Chemistry and Physicis, 467-474.

VON SPERLING, M. Introdução à qualidade das águas e ao tratamento de esgotos. Belo Horizonte: Departamento de Engenharia Sanitária e Ambiental; Universidade Federal de Minas Gerais, 2005. v. 1, 3 ed. 452 p.

WEE, T.H.; SURYAVANSHI, A.K; TIN., S.S. Evaluation of Rapid Chloride Permeability Test (RCPT) results for concrete containing Mineral Admixtures. ACI Materials Journal, USA: American Concrete Institute, v. 97, p. 221-232, 2000. 